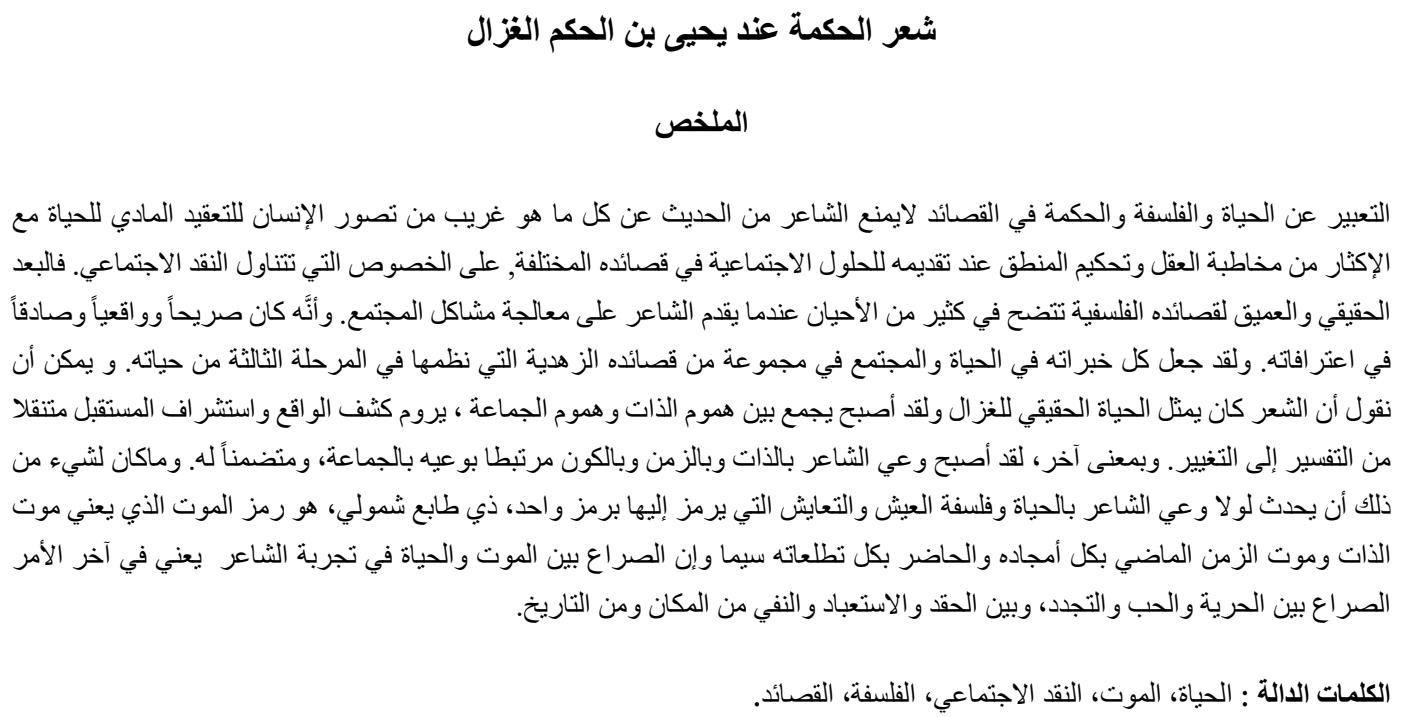

\title{
Yahya ibn el-Hakem el-Gazel'de hikmetli şiir
}

\section{Goran Salahaddin SHUKUR'}

APA: Shukur, G. S. (2019). Yahya ibn el-Hakem el-Gazel'de hikmetli şiir. RumeliDE Dil ve Edebiyat Araştırmaları Dergisi, (16), 693-702. DOI: 10.29000/rumelide.619704

\section{$\ddot{\mathbf{O} z}$}

Şair, felsefe ve hayatı anlatan şiirlerini yazdığı zaman insanların akıllarının alamayacağı kadar hayatın karmaşıklığını anlatmış ve aynı zamanda akla dayalı sosyal eleştirilerini yaparken çözüm önerilerinde sunmuştur. Özellikle sosyal eleştiri içeren şiirlerinde şair, sosyal ve toplumsal olayları anlattı̆̆ı zaman felsefi görüşlerini de ortaya koymuştur. Şairin görüşleri oldukça açık ve nettir. Şair, hayat tecrübesini özellikle hayatının son aşamasında yazmış olduğu dini şiirlerinde yansıtmıştır. Böylece şair hem kendi hem de hayatın sorunlarını anlamak için toplumun düşünce şeklini anlamaya çalışmıştır. Çoğu zaman şair, hayatı anlatırken ölüm ve yaşam temalarını şiirlerinde ele almıştır. Şaire göre yaşam ile ölüm arasındaki mücadele özgürlük, sevgi ve değişimin sembolüdür.

Anahtar kelimeler: Yaşam, ölüm, sosyal eleştiri, felsefe, kasideler.

\section{Abstract \\ Yahya ibn al-Hakam al-Kazal and his view toward life}

It is quite normal, for the poet, to express the philosophy of life and its wisdom through depicting the complexity of life in which man is living. In other word, the poet intends to present solution to Man who is confined with materialism throughout social criticism. In addition, the realistic and the profound view of life have been presented while the poet deals with social problems. In this sense, the poet is honest and realistic in his confession. In the third phase of his life, the poet composed a collection of poems which tackled with his own society as well as his experiences through ascetical

$1 \quad$ Doç. Dr., Selahaddin Üniversitesi, Diller Fakültesi, Arap Dili ve Edebiyatı Bölümü (Erbil, Irak), goselahattin1@yahoo.com, ORCID ID: oooo-0o01-8555-1941 [Makale kayt tarihi: 09.08.2019-kabul tarihi: 20.09.2019; DOI: 10.29000/rumelide.619704] 
poetry. Poetry, for Al-Kazal, demonstrates the real life in which he combined his personal and socialgrief. In other words, the poet becomes aware or conscious upon his self, time and universe. By doing so, the poet intends to say that life and its philosophy are related to each other. Death, for the poet, means the dead of soul and past time. Thus, the struggle between life and death in his poetical experiences means the struggle between freedom, love, hostility and slavery, expatriation from place and history on the other hand.

Keywords: Life, death, social justics, philosophy, poems.

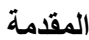

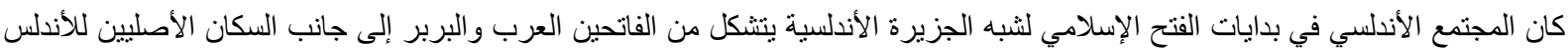

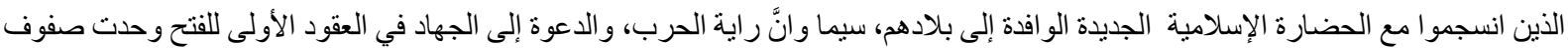

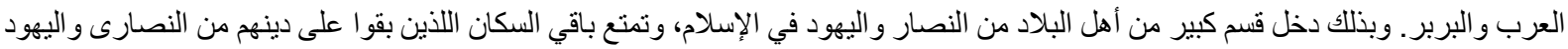

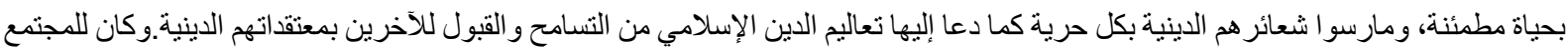

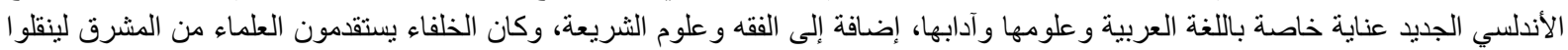

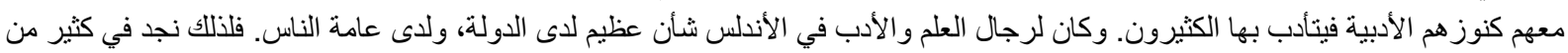

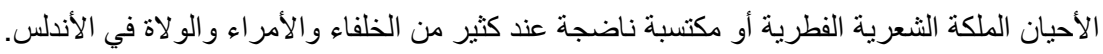

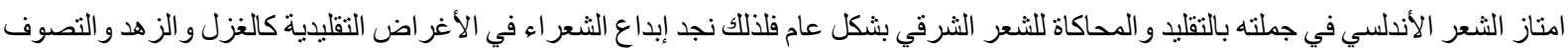

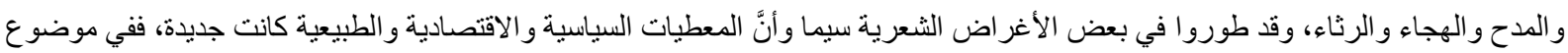

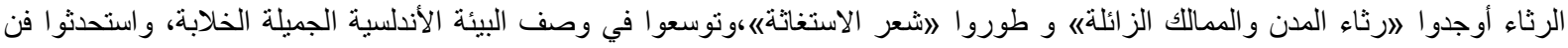

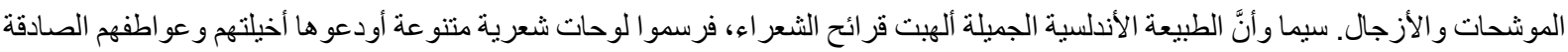

اشتهر الثعر اء في بدايات الفتح الاسلامي في الأندلس بكونهم من الطبقة الخاصة الحاكمة أو الحاثشية القريبة من الحكم سيما وأنَّ النظرة العامة في

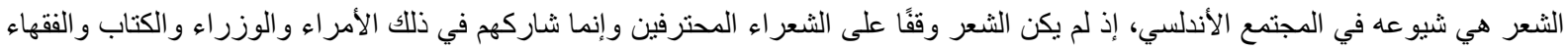

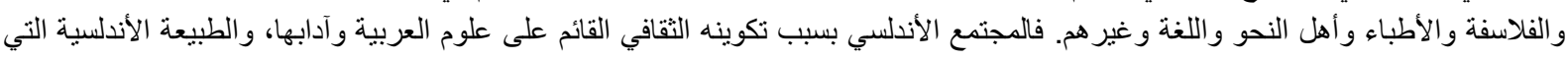

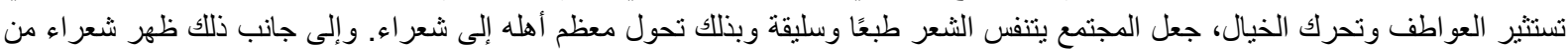

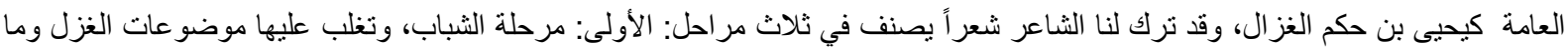

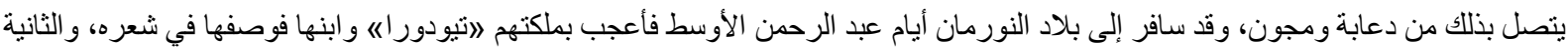

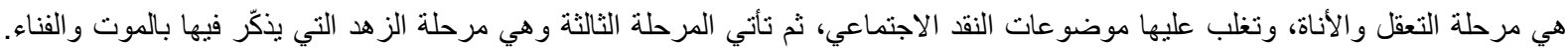

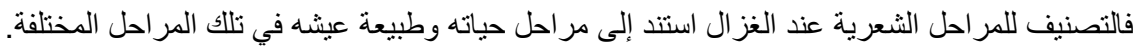

-روية الثاعر * في الحياة:-

الحياة كلمة شاملة تحمل في طياتها الزمان و المكان و الحضارة وتأثنيرات كل فب المجتمع والإنسان سيما و أنَّ الجمال والترف مع الرفاهية و اللهو

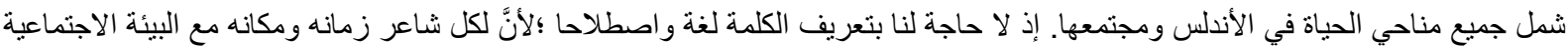

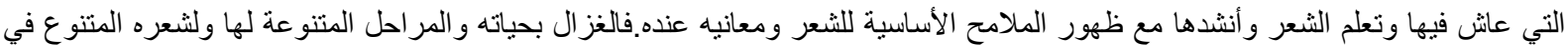

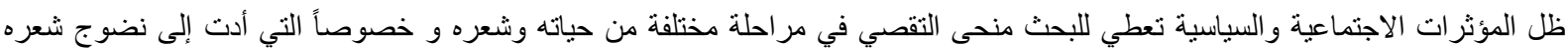

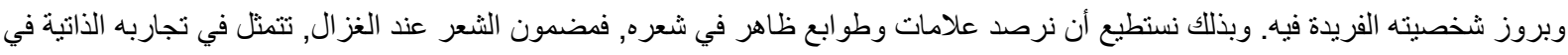

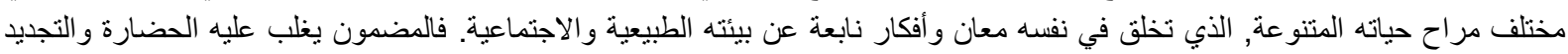

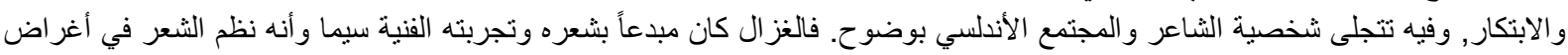

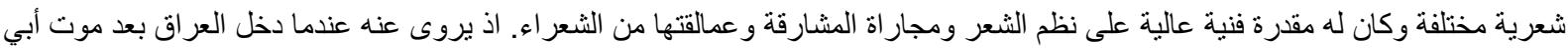

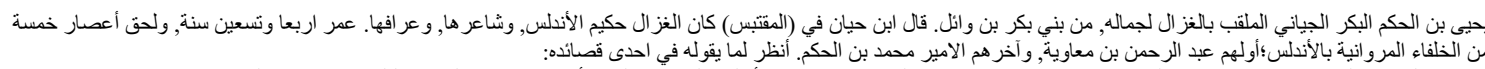

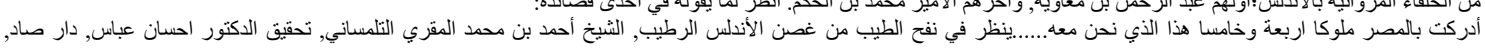
بيروت,ص ج2 (254. 
نو اس بمدة يسيرة, فوجد أهله يلهجون بذكره, و لا يساوون شعر احد بشعره, فجلس يوما مع جماعة منهم فأردوا بأهل الأندلس, واستهجنو ا أشعار هم,

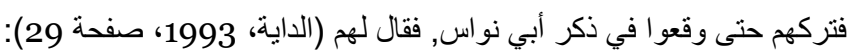

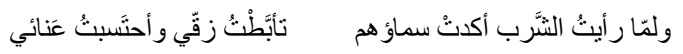

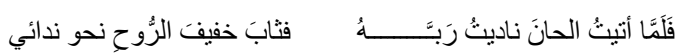

فأعجبو ا بالشعر , وذهبوا في دححه له, فلما أفرطوا قال لهم: خفضوا عليكم فأنه لي, فأنكروا ذلك, فأنثدهم قصبدته التي أولها (الداية، 1993،

صفحة 30):

$$
\text { تداركثُ في شُرب النَيْيذ خَطائي وفارقتُ فيه شيمتي وحَيائي }
$$

فلما أتم القصيدة بالإنثاء خجلوا , و افترقوا عنه (التلمساني، 2008، صفحة 261) هذا ما كان برى من التطابق التنام بين شاعر أندلسي وآخر

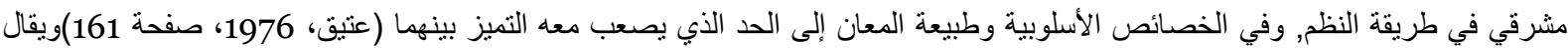

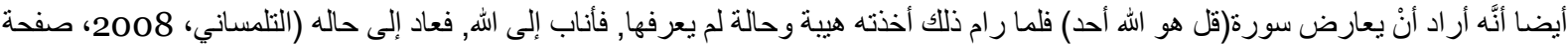

الدولة العربية الإسلامية بعهودها المختلفة في الأندلس أخذت تقارع المشارق وتضارع دولة بني العباس في المشرق و تنافسها في التقام العلمي

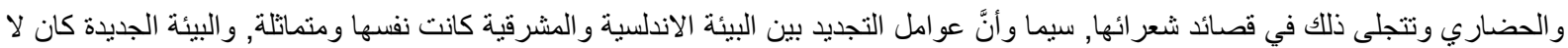

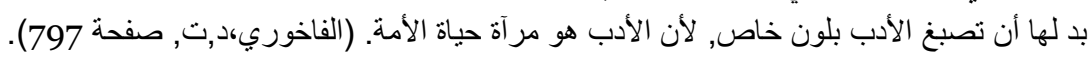

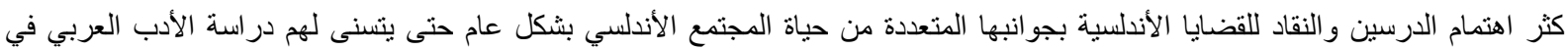

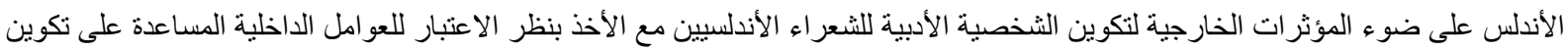

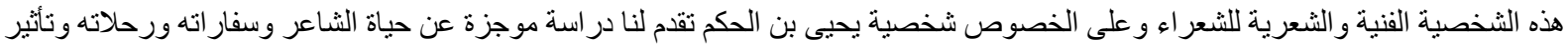

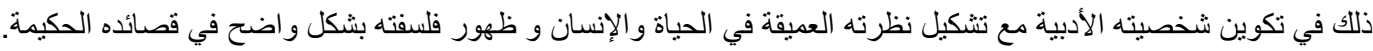

ممارسة الحياة والتعبير عنها والتعليق عليها عند الثاعر ونظرنه العميقة وفكره الفلسفي عن الحياة جعله يعبر تعبيراً صريحاً وسريعاً عما براه

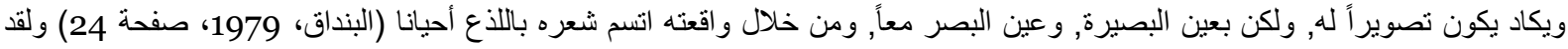

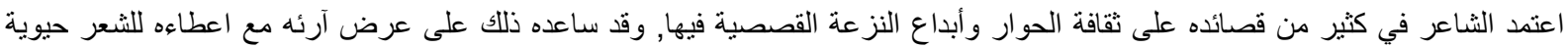

$$
\text { وحركة, وحرية في الآراء (الداية، 1993، صفحة 30):- }
$$

$$
\text { تداركتُ في شُرب النَّبيذِ خَطائي وفارقتُ فيه شيمتي وحَيائي }
$$

الحديث عن الثاعر وعن نظرته في الحياة والإنسان وأحو اله تستوجب منا أن نعرف أنه قد عاش حياة حافلة بمختلف أنواع الاستهتارو الإتزان

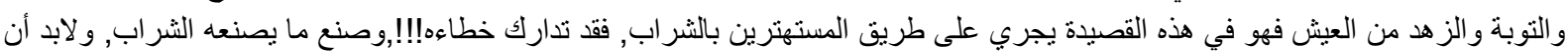

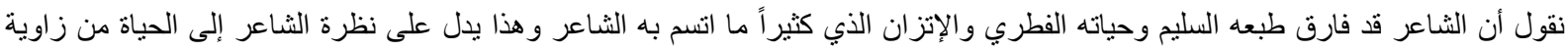

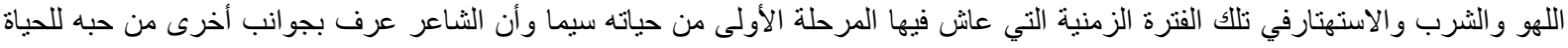

$$
\text { وتمسكه بها (الداية، 1993، صفحة 32):- }
$$

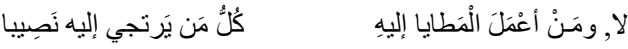

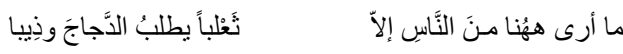

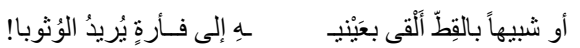

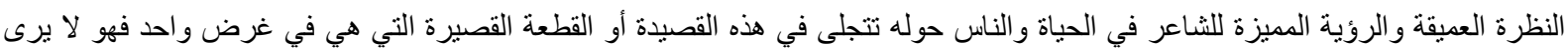

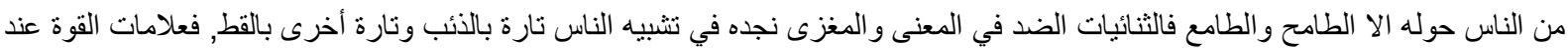

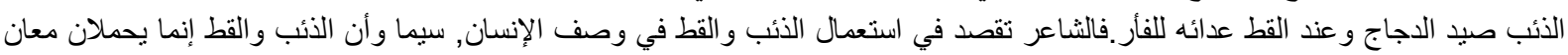

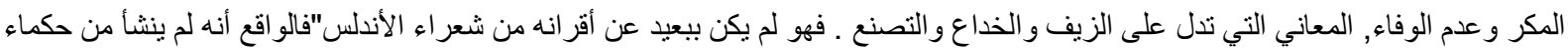

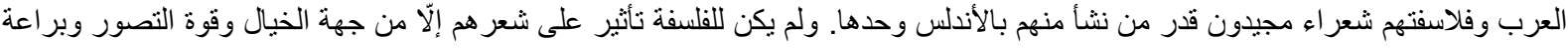

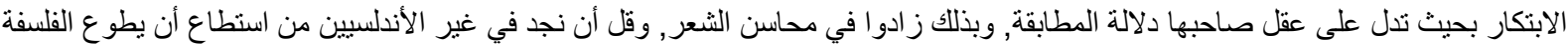

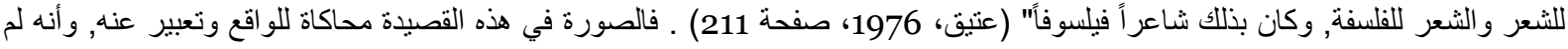


يخلق و اقعاً جديداً لم يعرفه الإنسان العربي في ظل العيش مع المعطيات الجديدة في الأندلس وكأن هذه الخصال صارت في كثبر من الناس حوله

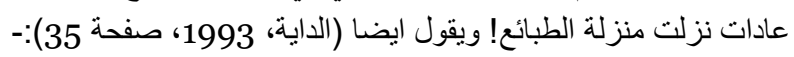

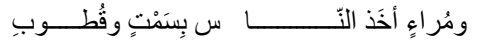

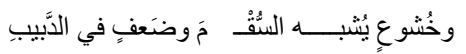

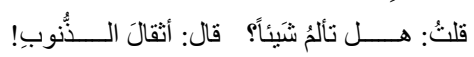

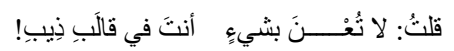

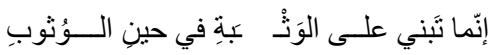

$$
\begin{aligned}
& \text { ليسَ مَنْ يَخس عليه }
\end{aligned}
$$

كانت المشاكل الاجتماعية التي عانى منها الجتمع العربي في الأندلس آنذالك من الموضوعات المهمة التي أثار ها الثاعر في كثير من قصائده سيما

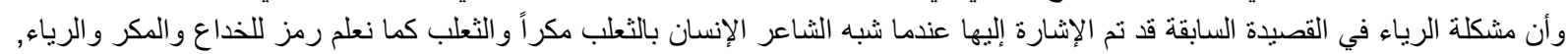

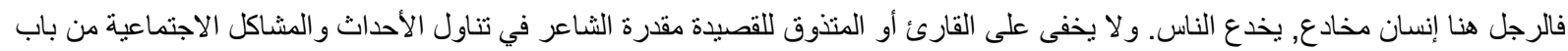

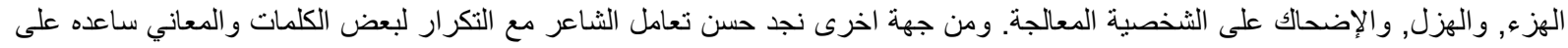

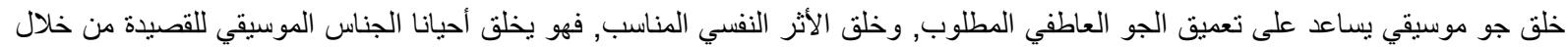

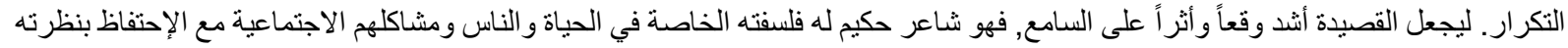

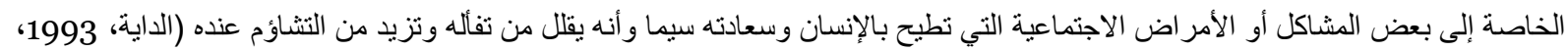

الصفحات (39-38).

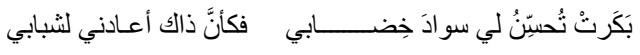

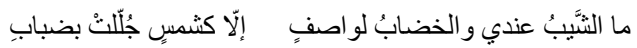

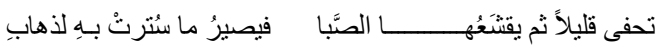

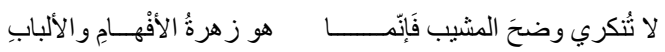

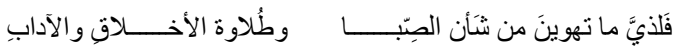

النهج اللطيف وحسن المعاني في هذه القصيدة إنما تدل على حكمة الثناعر وفلسفته في الحياة, ففي القصيدة حسن التعليل للشيب, ومحاولة لقلب ما

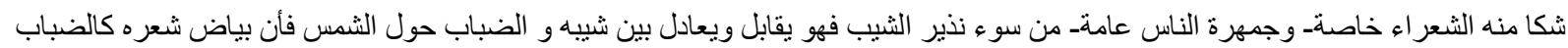

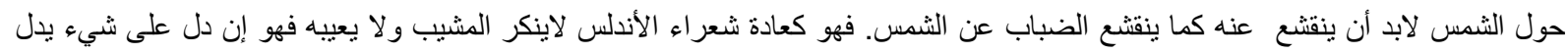
على العقل و الحكمة و التجربة.

- القلسفة و الفكر

الفلسفة والفكر إلى جانب الحكمة و أصالة الر أي وحسن التدبر كانت من الصفات المهمة للثاعر في قصائده عامة, فهو إلى جانب كل ما قلناه من

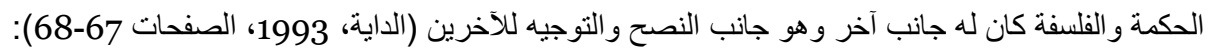

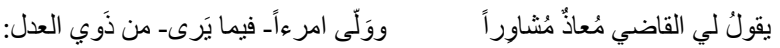

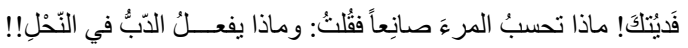

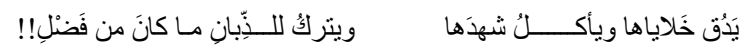

يقال عن معاذ بن عثمان الثعباني عندما ولي القضاء فيما بعد أخيه, وكان على عكسه طيباً, زاهداً, عابداً, خيراً ولكنه كان يعجل في اصدار الأحكام.

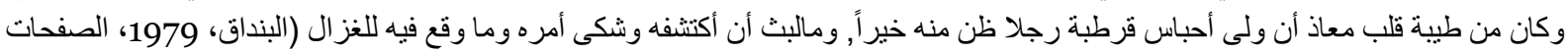

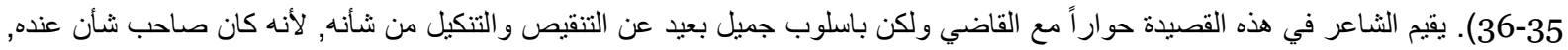

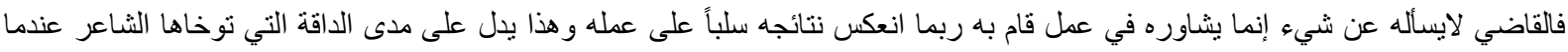

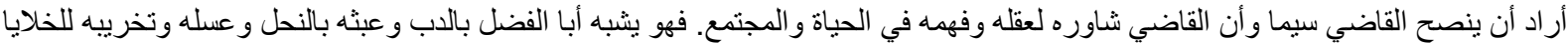
وتركه القليل من العسل حتى يستفيد منه الذباب. 


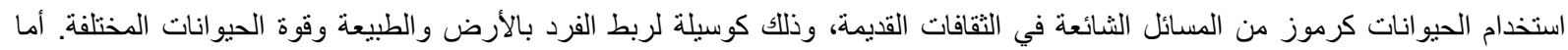

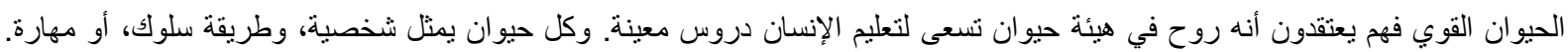

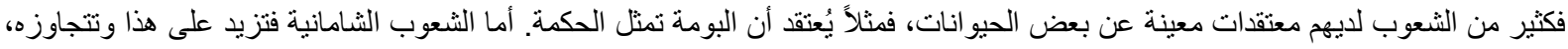

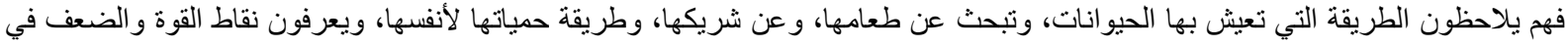

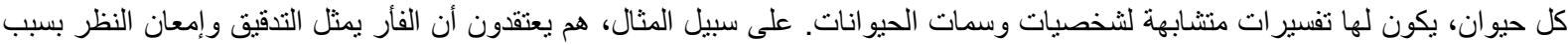

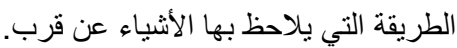

عندما يثبه الثاعر أبا الفضل بالدب دونا عن الحيو انات المفترسة الأخرى والتي كانت ترمز الى الجمال والقوة والثخصية العالية الرفيعة كان

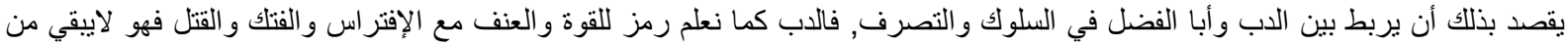

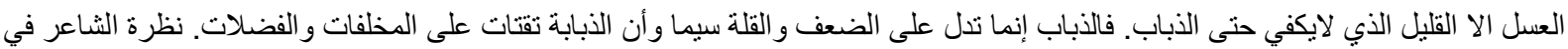

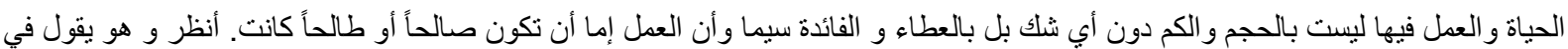

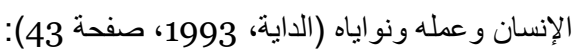

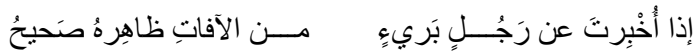

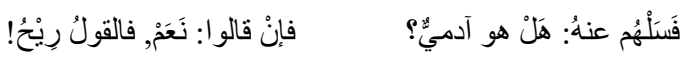

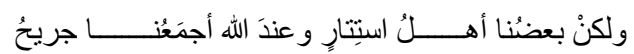

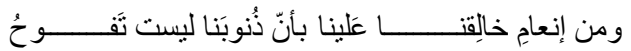

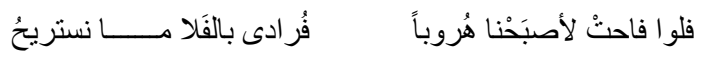

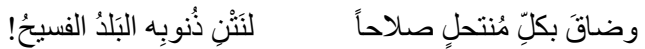

الحوار النوعي والذكي الذي أقامه الثاعر في مواقع كثيرة من أجل ما كان يقصدها من فكرة جليلة وصورة فنية رائعة تعبر عن الحيباة وما فيها

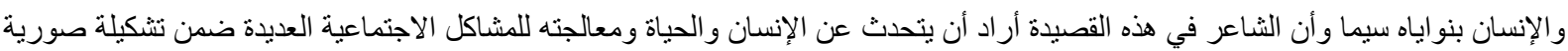

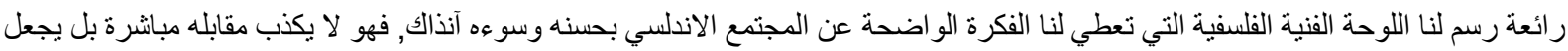
من الصورة الفنية سببا إلى جعل المقابل لكي يتأمل الحياة والإنسان حتى يعدل عن رأيه الظاهر و المغلق لقو انين الحياة و البشر التي تطيح به وبسعادته

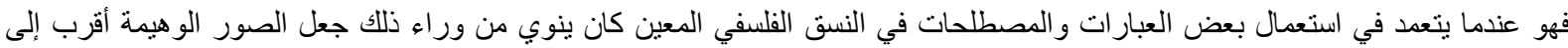

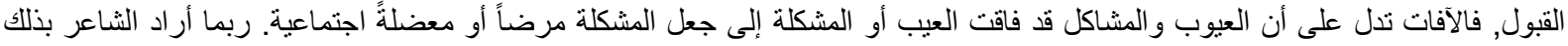

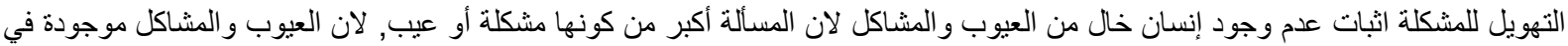

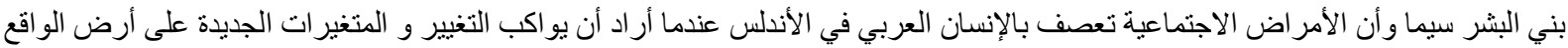

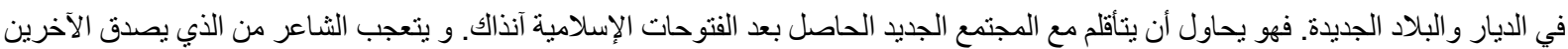

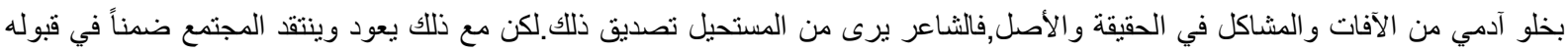

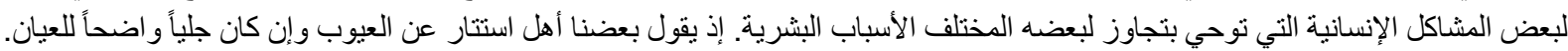

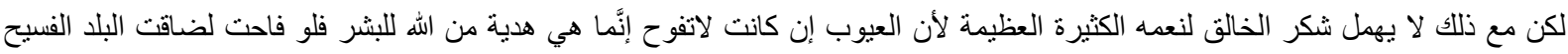
برائحة الذنوب و الخطايا الكثيرة و على الأخص من عيوب الذين يدعون بصلاح أحو الهم على خلاف ماهم عليه من الثأن والأحوال.

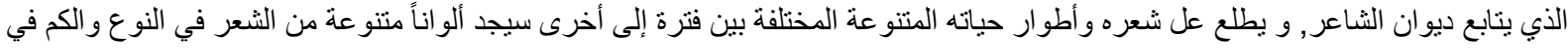

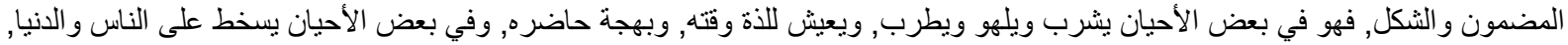

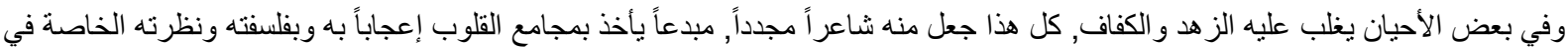

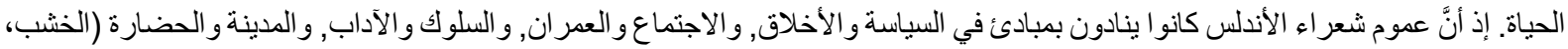

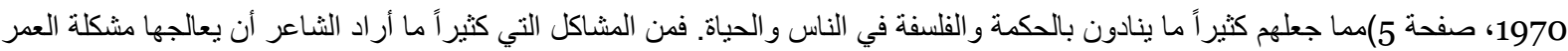

ونظرة الناس إلى الثيب و الفناء التي تجعل الإنسان في ظروف نفسية مختلفة صعبة (الداية، 1993، صفحة

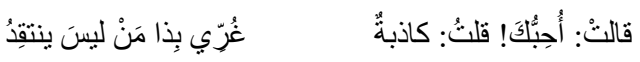

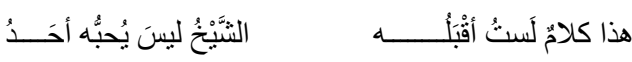

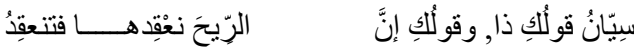

\footnotetext{
Adres | Adress 


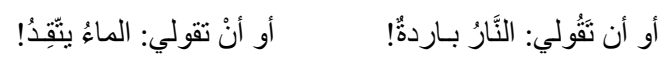

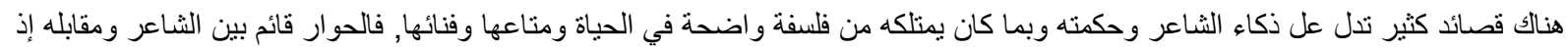

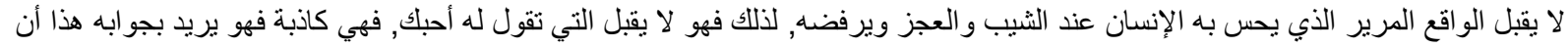

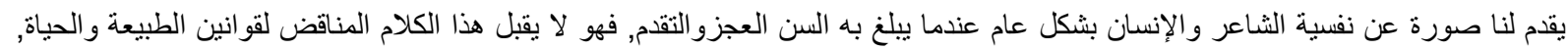

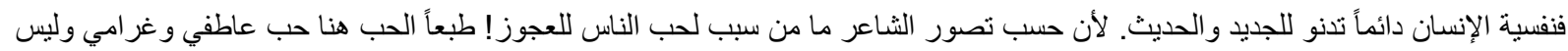

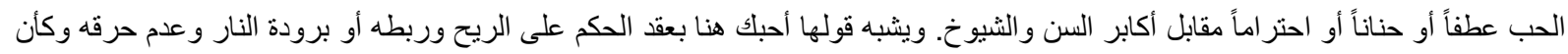

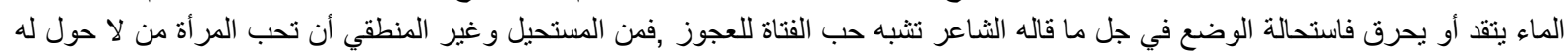
أو قوة لتقادم سنه و عجزه عن التمتع بالحياة ومتاعها.

بما أن الثاعر كان يتأثر بالحياة و عواملها المؤثرة على الثعر والفكر فأن التنوع والاختلاف في أطوار الحياة لديه ولد شعر أ ذا طابع فلسفي وحكمي

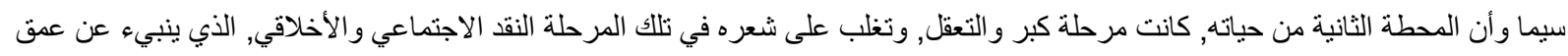

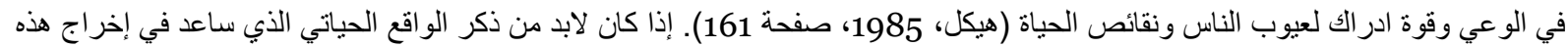

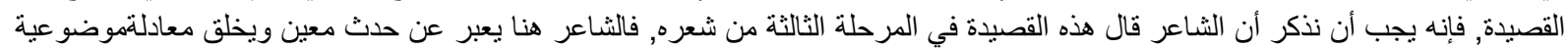

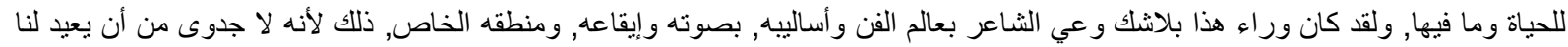

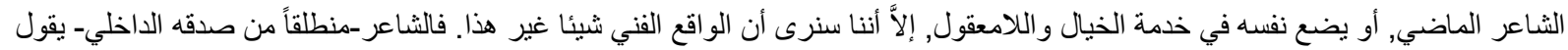

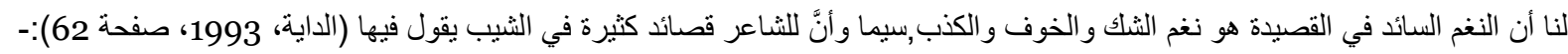

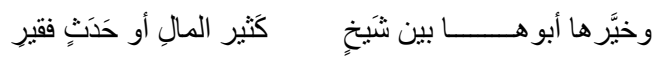

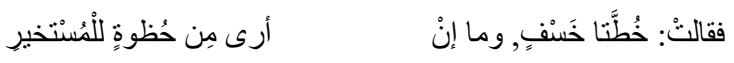

$$
\begin{aligned}
& \text { ولكنْ إن عَزمْتَ فكلُ شيء }
\end{aligned}
$$

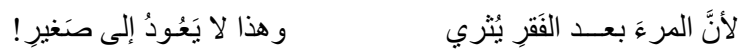

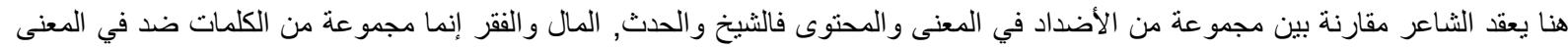

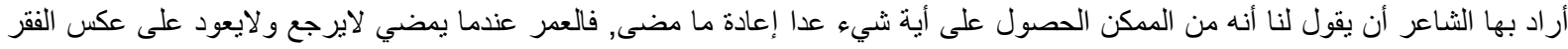

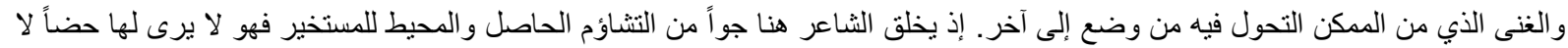

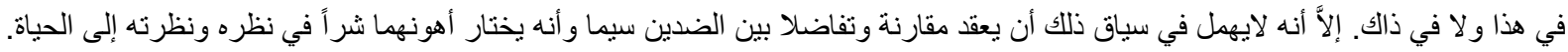

-الزهد والتصوف والدهر

القصيدة"مونولوج داخلي" يفكر فيه المستخير بصوت مسموع للتنفيس عن نفسها. فالثاعر هنا يستشفي بالثعر لأنه في حالة تونر ومعاناة,سيما وأنَّه

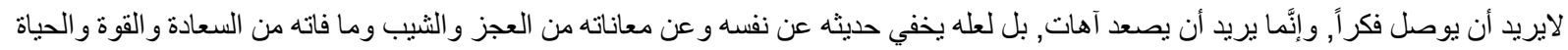

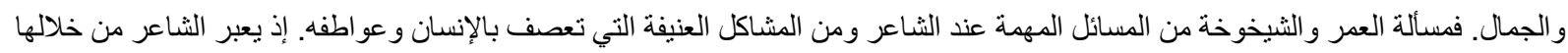

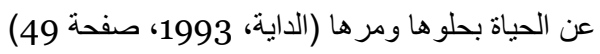

$$
\begin{aligned}
& \text { إنّي حلبثُ الدَّهر أصنافت الدّرَزْ }
\end{aligned}
$$

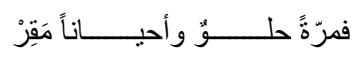

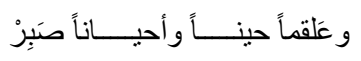

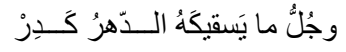

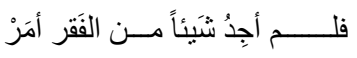

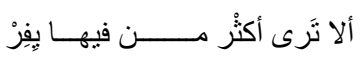

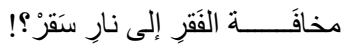

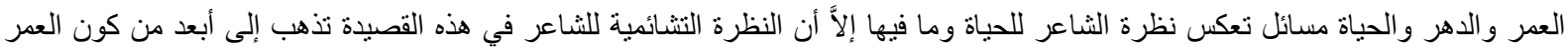

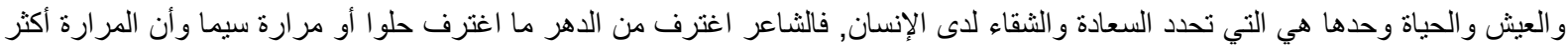

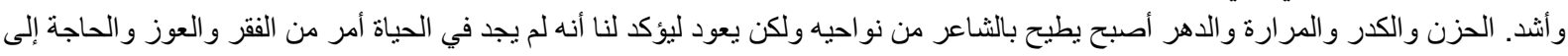


الآخرين.إذا نظرنا إلى لغة القصيدة نجد فيها طلاوة, سيما وأن الحزن و التعاسة و المر ارة, تنبثق من الدهر و العمر و أنها تتر اوح بين الحلاوة و المرارة.

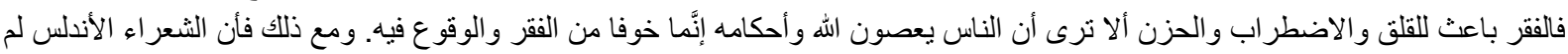

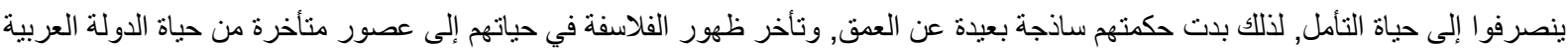

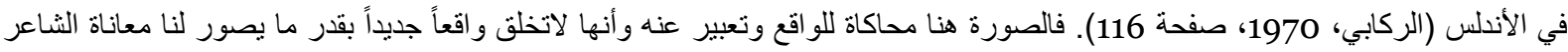

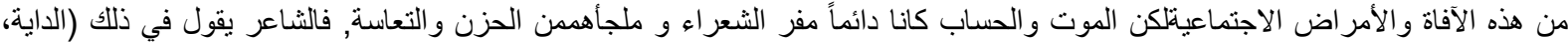

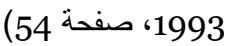

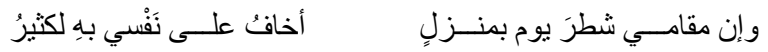

$$
\begin{aligned}
& \text { وقد يهرُب الإنسان من خِيفة الرّدى فيدركُه ما خافت حيثُ يَسيرُ ! }
\end{aligned}
$$

خوف الإنسان من هذا وذالك لايحول بينه وبين الموت وأجله, فأنفعال الثناعر بالحياة وما فيها من المخاوف تسوقه دائما إلى مو عده مع القدر. الحكمة

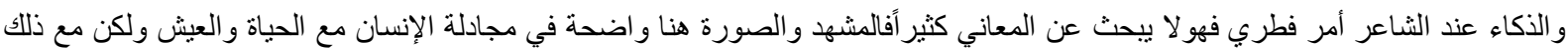

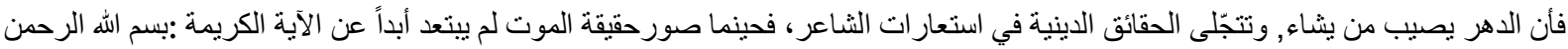

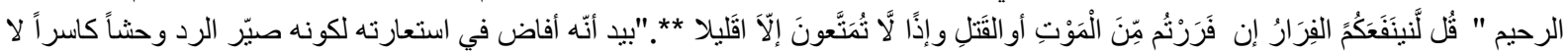

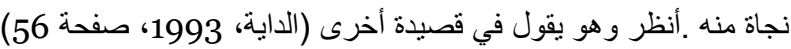

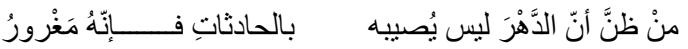

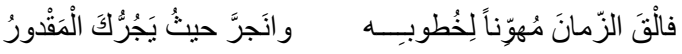

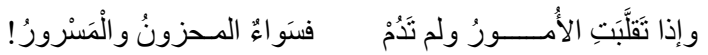

لقد أكثر الشاعر من استعمال ثنائيات الضد في قصائده، فالدهر في هذه القصيدة من منظور الثاعر ورؤيته إلى القدر ومحكومية الإنسان فيه هو القياء

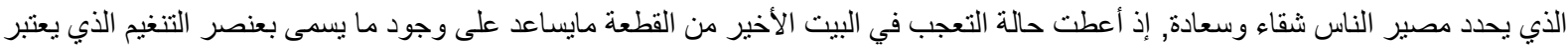

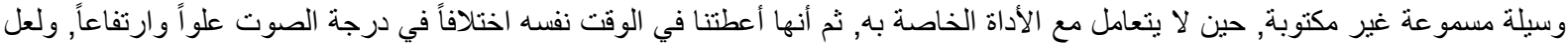

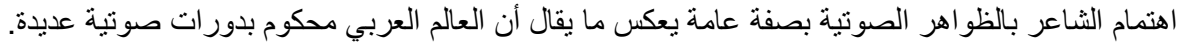

هناك اسقاطات من الثاعر بحيث نعرف منه شيئا عن الفترة التي عاش فيها. فالو اقع أنه لم ينشأ من حكماء العرب وفلاسفتهم شعر اء مجيدون قدر

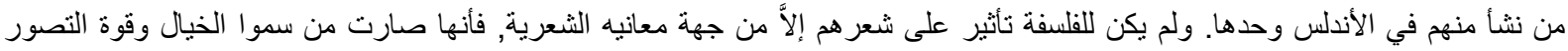

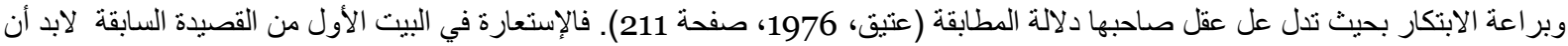

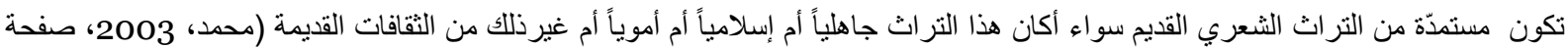

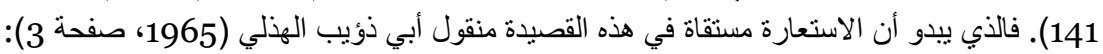

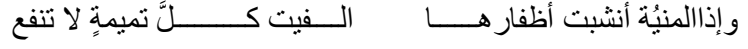

$$
\begin{aligned}
& \text { إن لم تكون منقو لا لنابغة الذبياني (ابر اهيم، 1985، صفحة 227): }
\end{aligned}
$$

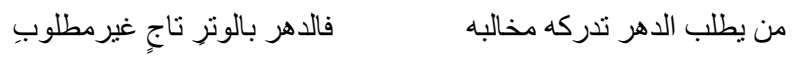

وحينما يتقلب الأمور و الأوضاع فما من شيئا يعين الإنسان على أن يقلب وضعه سواء كان شقياً أو سعيداً فالحزن والسرور سيان عند الثاعر سيما

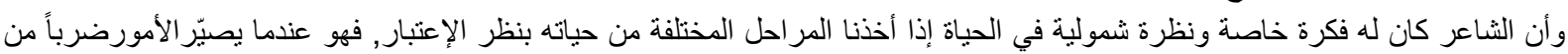

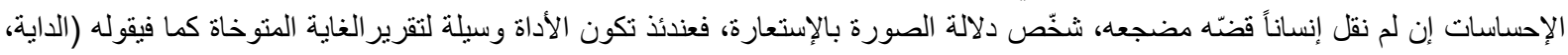

1993، صفحة 56 الإنمات

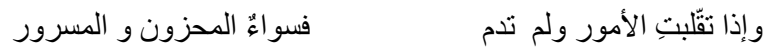


عند حديثنا عن فلسفة الثاعر ورؤيته في الحياة لابد أنْ نشير إلى احدى أهم قصائده التي نظمها في فترة الزهد من حياته و التي تدل

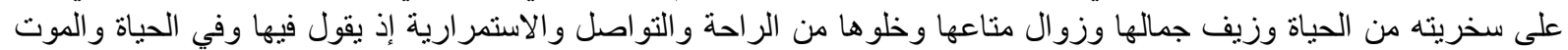

(الداية، 1993، صفحة 61)

$$
\begin{aligned}
& \text { أرى أهــــلـل اليسار إذا توفُوَا }
\end{aligned}
$$

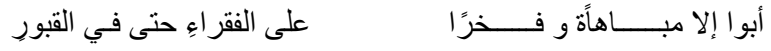

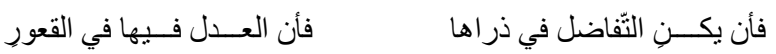

$$
\begin{aligned}
& \text { رضيت بمن تأنّق فـي بنــاءٍ }
\end{aligned}
$$

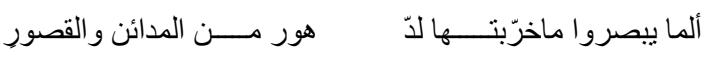

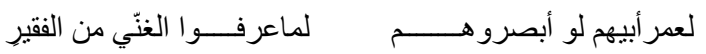

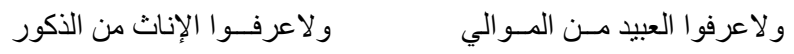

$$
\begin{aligned}
& \text { و لامن كان يلبس ثوب صوفٍ مــــن البدن المباشر للحرير }
\end{aligned}
$$

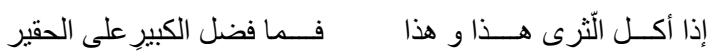

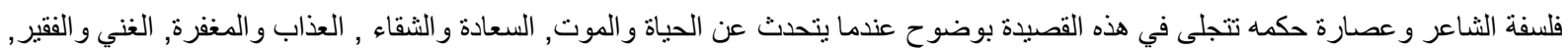
القصور و القبور. كم هائل من المعاني الأخاذة استعمله الثاعر في هذه القصيدة من أجل إحكام سيطرته على المعاني حتى يتسنى للسامعين الأخذ

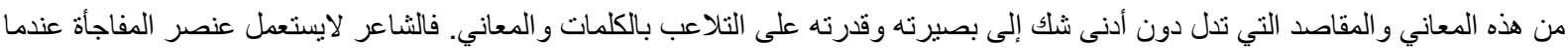

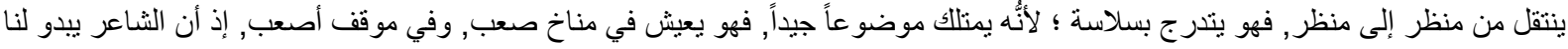

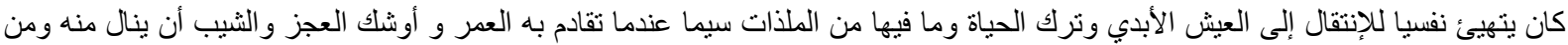

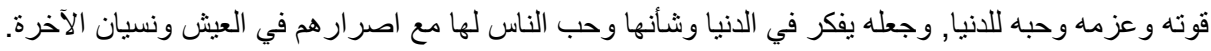

اذ أنَّ اهل اليسار تمتعوا بالعيش في حياة الدنيا حتى أنساهم الدنيا وما فيها سيما وأن الحياة تزول والإنسان فان إلاًّ أن الغرور بالعيش والإصرار

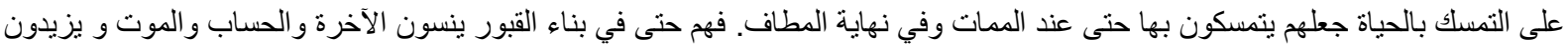

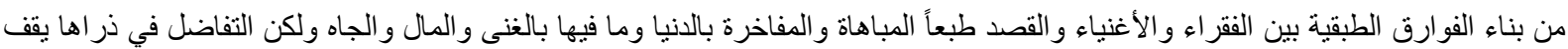
عاجزاً بين القبور و العدل بين الاخرة و الدنبا والمساو اة فيها, فالغني غني في الدنباو الفقير العابد السابح بعمله غني في القبر و الآخرة.

عندما بدء الثاعر بذكر القبور و التفاضل والمباهاة عند أهل اليساري من الأغنياء كان يقصد بذلك التطرف و الغلو والإسراف و التأنق في الحياة وما

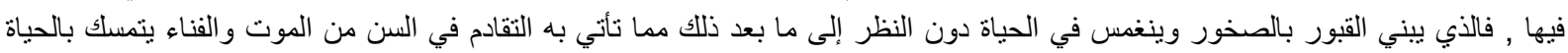

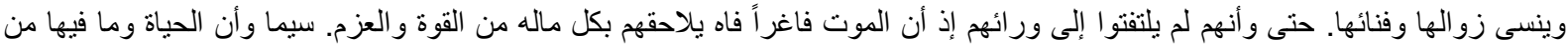

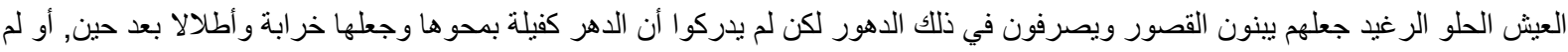
يبصروا إلى ما خربته الدهور من القصور و المدن. ولكن أين ذللك البصيرة و النظرة العميقة للحياة والموت عند ناس أخذهم العزة بالنفس و الحياة.

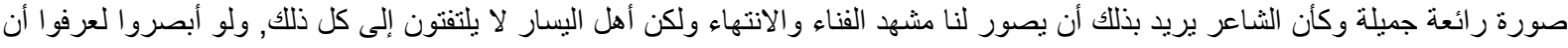

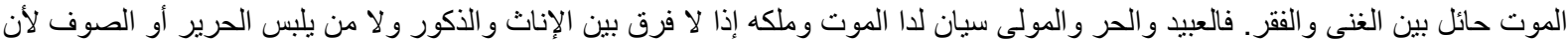

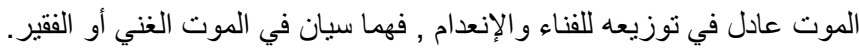

شخصية الثاعر تبدو و اضحة لنا في هذه القصيدة الر ائعة في تلك المرحلة من مر احل حياته, اذ أن الثاعر كان متفاعلاً مع أحداث عصره السياسية

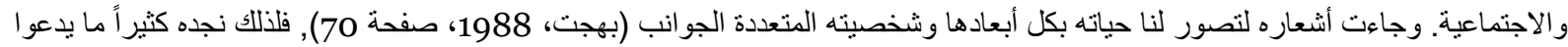

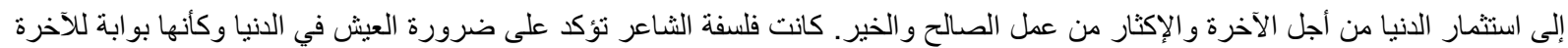

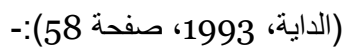

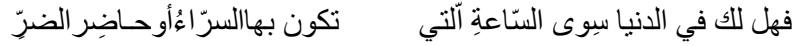

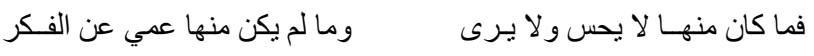

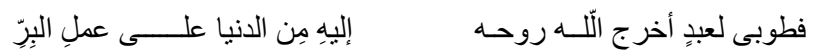

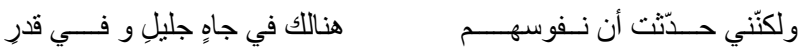




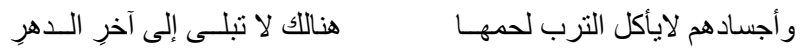

لا تعني الدنيا للشاعر سوى ساعة تكون بها السر اء أو الضر اء. فهي لاتفيد و لا تجدي لو كان الإنسان مفكراً في الأمر. فالإنسان الصالح في الحياة

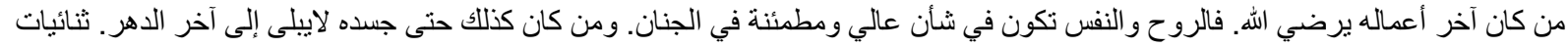

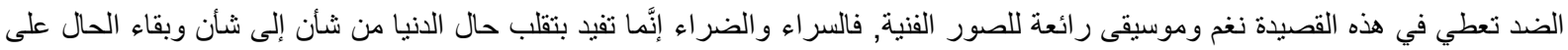

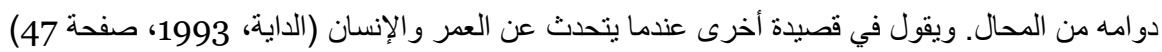

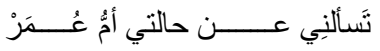

$$
\begin{aligned}
& \text { وهي تَرى ما حلّ بي مــن الـــغِيَرْ }
\end{aligned}
$$

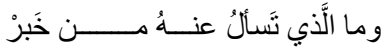

$$
\begin{aligned}
& \text { وقد كَفَاهَا الكشثفُ عــن ذاكَّ النَّظر } \\
& \text { وما تكونُ حالـتـي مـــع الــــــــكِبَر } \\
& \text { اربدَّ مـــنـي الــــوجهُ و أبيضَّ الثَّعز } \\
& \text { وصـار رأسي شُهـــــةًَ مـن الثُهَهْ }
\end{aligned}
$$

العمر و السن والثيخوخة من أكثر ما تتاوله الثاعر في التعبير عن الحياة والفلسفة والحكمة إذ أن حالته تعبر عن نقادم سنه وتدهور نفسيته, ولكن

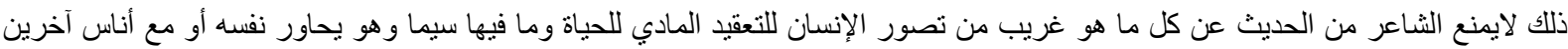

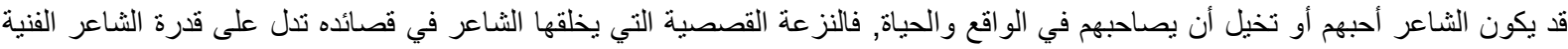
و اللغوية مع الإكثار من مخاطبة العقل وتحكيم المنطق عند تقديمه للحلول الاجتماعية في قصائده المختلفة, على الخصوص التهي التي تتناول النقد

البعد الحقيقي والعميق لقصائده الفلسفية تتضح في كثير من الأحيان عندما يقدم الثـاعر على معالجة مشاكل المجتمع. يقول الدكتور حكمة علي

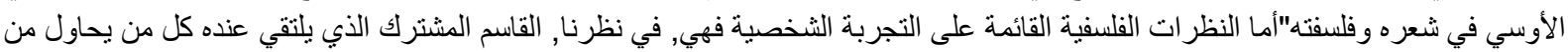

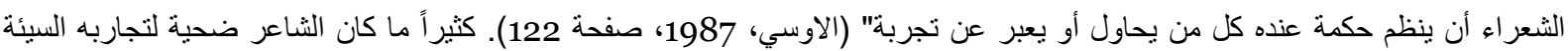

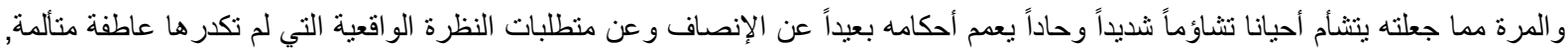

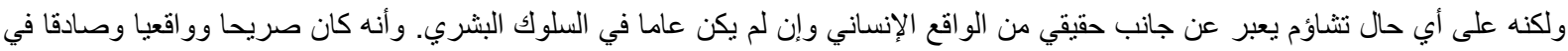

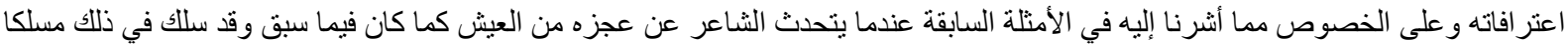

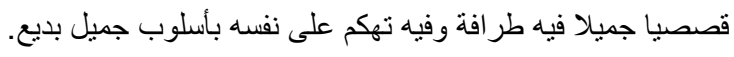

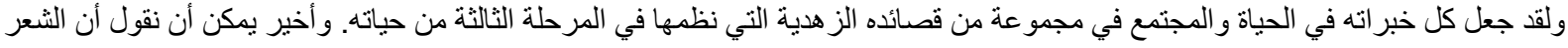

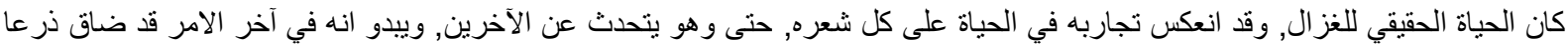

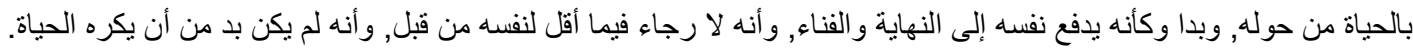

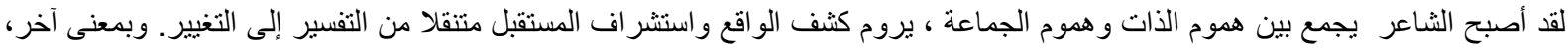

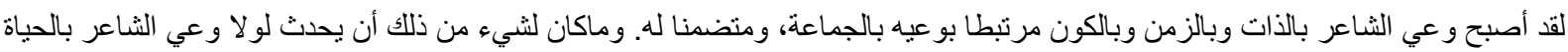

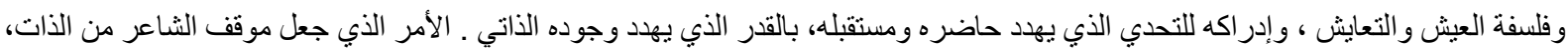

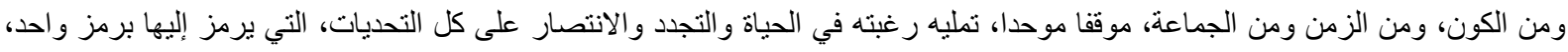

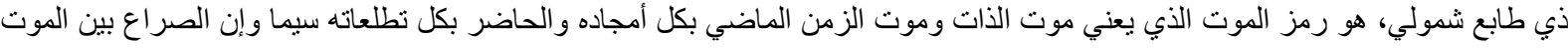
و الحياة في تجربة الثاعر يعني في آخر الأمر الصر اع بين الحرية والحب و التجدد، وبين الحقد والاستعباد و النفي من المكان ومن التاريخ.

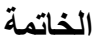

شخصية الثناعر بمختلف جو انب شعره وجو انب من تاريخ الدولة في الأندلس تقدم لنا دراسة موجزة عن حياته وسفار اته ورحلاته وتأثير ذلك في

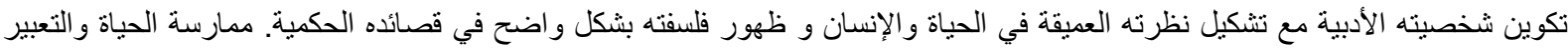

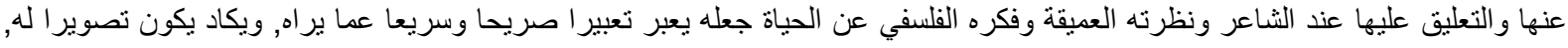
ولكن بعين البصيرة, و عين البصر معا. ولقد جعل كل خبر اته في الحياة والمجتمع في مجموعة من قصائده الزهدية التي نظمها في المرحلة الثالثة 
من حياته.بذللك أصبح الثـاعر يجمع بين هموم الذات وهموم الجماعة ، ويروم كثف الو اقع واستشر اف المستقبل متنقلا من التفسير إلى التغيير.

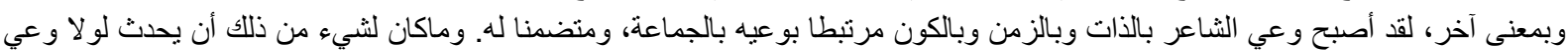
الثاعر بالحياة وفلسفة العيش و التعايش.

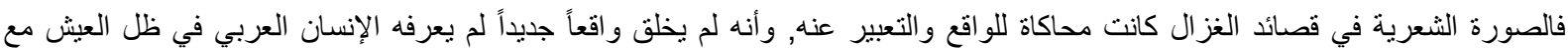

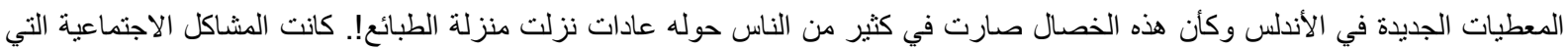

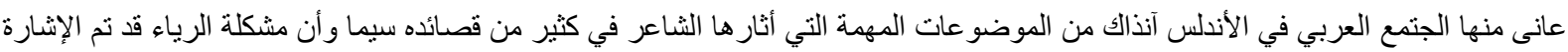

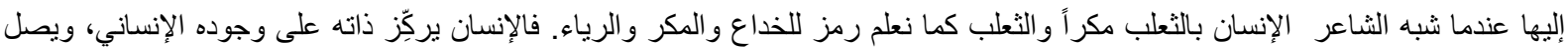

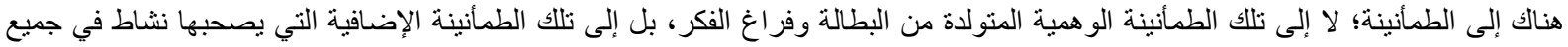
القوى و العلاقات.

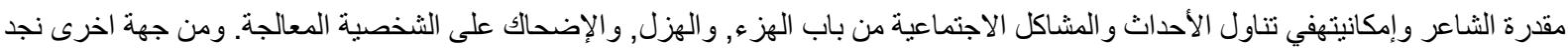

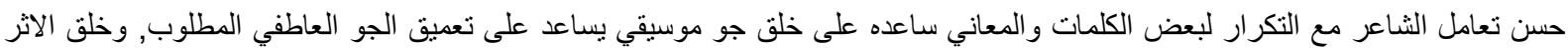

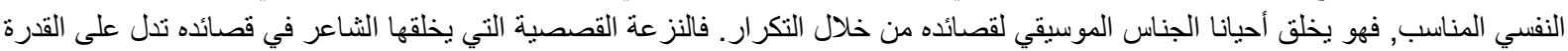

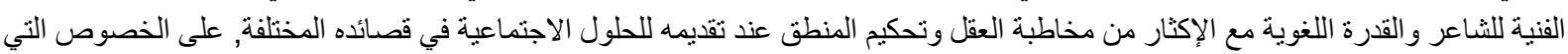

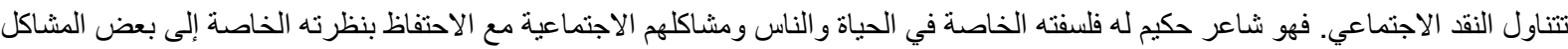

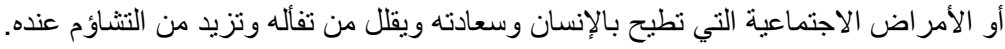

الفلسفة والفكر إلى جانب الحكمة و أصالة الر أبي وحسن التدبر كانت من الصفات المهمة للشاعر في قصائده عامة, فهو إلى جانب كل ما قلناه من

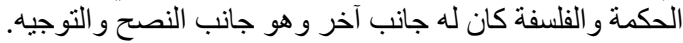

\section{Kaynakça}

Abu Fazıl İbrahim, Muhammed (1985). Divanün-Nabiga ez-Zübyani. 1.Baskı, Kahire: Darul'l Ma'rifa. Abu'l- Haşab, İbrahim Ali (1970). Tarihu’l-Edebi'l-'Arabî el-Endelüsî. Kahire: Daru'l-fikri'l-Arabi Atik, Abdülaziz (1976). Edebi'l-'Arabî fi el-Endelüsî. Beyrut: Darul el-Nehza el-Arabî.

Behçet, Müncid Mustafa (1988). Edebü'l-Endelüsî min Fethi hatta sukûtî Granadatu. Musul: Daru'lKutup.

el-Avsi, Hikmet Ali (1987). Fusulûn fi'l-Edebu'l-Endelûsi fi Karneyin el-Sani ve'l-Salisi'l-Hicreti. 5. Baskı, Bağdat: Babil.

el-Bendak, Muhammed Salih (1979). Yahya bin Hakem el-Gazal Emirü'ş-Şuara el-Endelûs fi karni’ssalis el-hicri. 1.Baskı, Beyrut: Daru'l-afaki'l-cedidetun.

el-Dayye, Muhammed Razvan (1993). Divanu Yahya bin Hakem el-Gazal. Beyrut: Daru'l-fikri'l-muasir. el-Fahuri, Hinnal (1960). Tarihu’l-Edebi’l-'Arabî. Beyrut: Polisiyye.

el-Makkari el- Telmesani, Ahmet bin Muhammed (2008). Nefhu’l teyip min husun el-endülüs el-ratiyip. Beyrut: Daru's-sadr.

el-Rukabi, Cevdet (1970). Fi’l-Edebu’l-Endelûsi. 3.Baskı, Kahire: Daru’l-Ma'rif.

el-Zeyin, Ahmet ; Abu'l-Vefa, Mahmut (1985). Divan el- Hazeyliyin. Kahire: Daru'l-Kavmiyye.

Heykel, Ahmet (1985). el-Edebü'l-Endelusî mine’l-Fethi ila Sukuti’l-Hilafe. Kahire: Daru'l-Ma'rif.

Muhammed, Muhsin İsmail (2003). es-Sure'ş-Şaariye fi Şiiri Yahya bin Hakem el -Gazal el-Endelusi, (Granada: Granada üniversitesi,). 